\title{
Immunohistochemical localization and quantitative assessment of GnRH-, FSH-, and LH-receptor mRNA Expression in canine skin: a powerful tool to study the pathogenesis of side effects after spaying
}

\author{
Monika M. Welle • Iris M. Reichler • Andrea Barth • \\ Ursula Forster · Ursula Sattler · Susi Arnold
}

Accepted: 21 April 2006 / Published online: 20 May 2006

(C) Springer-Verlag 2006

\begin{abstract}
It has been proposed that gonadotropins and/or gonadotropin releasing hormone $(\mathrm{GnRH})$ could be involved in the pathophysiology of the side effects after spaying in bitches, such as urinary incontinence and an increased production of a woolly undercoat. In order to provide tools to investigate the role of these hormones in dogs we developed immunohistochemical techniques and real-time RT-PCR to study whether GnRH-, LH-, and FSH-receptors exist in canine skin and urinary bladder. Tissue samples from the skin of the flank region and the ventral midline of the urinary bladder from euthanised dogs were examined. We were able to quantify mRNA expression of GnRH-, FSH-, and LH-receptors in canine skin and bladder biopsies with a high primer efficacy. Immunohistochemical studies showed that GnRH-, FSH-, and LH-receptors are expressed in vessel walls, the epidermis, the hair follicle and in sebaceous and sweat glands in canine skin and in transitional epithelium, and smooth muscle tissue in the urinary bladder. Our data provide the fundamentals to examine the distribution of FSH-, LH-, and GnRH-receptors in canine skin and urinary bladder and to assess gene activity at the transcriptional level by real-time RT-PCR.
\end{abstract}

M. M. Welle $(\bowtie) \cdot$ U. Forster $\cdot$ U. Sattler

Institute of Animal Pathology, Vetsuisse Faculty,

University of Berne, Postfach, Längassstr.122,

3014 Berne, Switzerland

e-mail: monika.welle@itpa.unibe.ch

I. M. Reichler · A. Barth $\cdot$ S. Arnold

Section of Small Animal Reproduction,

Department of Small Animals, Vetsuisse Faculty,

University of Zürich, Winterthurerstr. 260,

8057 Zurich, Switzerland
Keywords FSH receptor $\cdot$ LH-receptor $\cdot$ GnRHreceptor $\cdot$ Canine $\cdot$ Skin $\cdot$ Urinary bladder

\section{Introduction}

Gonadotropin releasing hormone $(\mathrm{GnRH})$ is a decapeptide that is secreted from the hypothalamus and acts as an important regulator of endocrine and reproductive functions (Kaiser et al. 1997). It binds to the high affinity GnRH-receptor (GnRHR) in the anterior pituitary gland (Perrin et al. 1993) and stimulates the synthesis and release of the pituitary gonadotropins luteinizing hormone (LH) and follicle-stimulating hormone (FSH), which regulate the mammalian reproductive process (Kakar et al. 1992). Studies have indicated that GnRH can also effect the secretion of hormones and cell functions of nonpituitary tissues and its receptor exists in other tissues such as ovary, testis, placenta, adrenal, breast, and prostate gland (Jennes et al. 1988).

Luteinizing hormone binds to a transmembrane glycoprotein (LHR), which is a member of the G protein coupled receptor family (Sun and Davies 1995). This receptor plays a fundamental role in ovarian responsiveness to pituitary LH. Besides ovaries, LHR immunoreactivity was also found in other tissues, such as brain, fallopian tube, endometrium, trophoblasts, smooth muscle cells, skeletal muscle fibres, fibroblasts, and resident tissue macrophages (Bukovsky et al. 2003). Furthermore, LHR have been described in human skin (Pabon et al. 1996; Venencie et al. 1999).

Follicle-stimulating hormone which is required for normal reproductive function in all mammals binds like $\mathrm{LH}$ to a $\mathrm{G}$ protein coupled receptor (FSHR) (Khan et al. 1997). FSHR are found on Sertoli cells in 
males and on granulosa cells in females (Hsueh et al. 1989; Orth and Christensen 1977).

The interaction of FSH and LH with their receptors stimulates the production of sex hormones, such as estrogens, testosterons, and progesterons (Ashley et al. 1999). So far receptors for androgens (Blauer et al. 1991; Choudhry et al. 1992; Liang et al. 1993), estrogens (Hasselquist et al. 1980), and progesterone have been described in the skin of human beings (Mowszowicz et al. 1982).

In bitches common side effects of spaying are urinary incontinence (Holt and Thrusfield 1993) and an increased production of a woolly undercoat, leading to a so-called "puppy coat"(Scott et al. 2001). Until recently all side effects of spaying were thought to be mainly due to an estrogen deficiency after ovarectomy. However, estrogen deficiency has never been proven as the underlying cause (Reichler et al. 2005; Scott et al. 2001). There are some facts that do not support estrogen deficiency as underlying cause. For the longterm postponement of oestrus intact bitches are treated with depot-gestagens, which results in ovarian quiescence. Incontinence of the type seen in spayed bitches has not been reported and rarely coat changes do occur.

Some publications indicate that gonadotropins could be involved in the pathophysiology of the side effects after spaying. After removal of the ovaries the negative feedback of the gonadal hormones is interrupted. Thus the plasma concentration of the gonadotropins increases several folds (Olson and Nett 1992; Reichler et al. 2005, 2004), a phenomenon which is also observed in post-menopausal women (Wise 1999).

LHR have been demonstrated in hair follicles (Pabon et al. 1996) and in the urinary bladder (Tao et al. 1998) in human beings. A further indication that the expression of LHR could play a role in the side effects after spaying and menopause, respectively, is the fact that in urinary bladders of menopausal women significant lower mRNA levels for LHR were demonstrated than in cycling women (Tao et al. 1998). Furthermore, bitches which developed urinary incontinence after spaying have significantly lower GnRH plasma levels than controls and treatment with $\mathrm{GnRH}$ analogs proved to be curative (Reichler et al. 2003, 2005).

Based on this and in order to provide morphologic and molecular biological evidence for further functional studies in the dog we developed immunohistochemical techniques and real-time RT-PCR to study whether GnRH-, LH-, and FSH-receptors exist in canine skin and urinary bladder and in which cells they are localized.

\section{Materials and methods}

Tissues

Tissue samples from the skin of the flank region and the ventral midline of the urinary bladder from ten freshly euthanised dogs between 4 and 11 years of either sex were examined in this study. As positive control for the detection of the GnRHR and its mRNA pituitary glands were used. Ovaries taken during spaying were used as positive controls for LHR and FSHR. Since it is for now unknown, which tissue does not express any of these receptors we used cells from longterm keratinocyte cultures as negative control, assuming that receptor expression is negative after a prolonged absence of endocrine stimuli.

For immunohistochemistry (IHC) biopsies and control tissue were fixed in buffered formalin $(4 \%)$ at room temperature for $24 \mathrm{~h}$. The biopsies and controls were then embedded in paraffin wax and serial sections of $4 \mu \mathrm{m}$ were cut from each tissue block.

Messenger RNA extracted from tissue samples, which had been stored in RNAlater (Ambion; Catalogue No. 7020 ) at $4{ }^{\circ} \mathrm{C}$ was analysed employing quantitative real-time PCR.

mRNA extraction and quantitative real-time RT-PCR

Real-time RT-PCR was performed to quantify the production of mRNA of GnRH-, LH-, and FSH-receptors. The values were normalized using the housekeeping gene ribosomal (r)18 S. Before RNA extraction, biopsies were homogenized with a Polytron PT 1,600E. RNA extraction was performed according to the instructions for the use of Quiagen RNeasy-Fibrous Tissue Mini Kit (Quiagen). After extraction, RNA was dissolved in $50 \mu \mathrm{l}$ of RNase-free water and the concentration of purified total RNA was determined measuring the optical density at $260 \mathrm{~nm}$. Two $\mu$ g of each RNA sample were reverse transcribed into cDNA using random hexamer primers (Promega, Catalys AG; Wallisellen, Switzerland) in a final reaction volume of $50 \mu \mathrm{l}$. Primers and fluorescent FAM-labeled probes were designed in-house from published sequences using the PrimerExpress software (Applied Biosystems, Foster City, USA). The sequences of the primers and probes are shown in Table 1. Real-time PCR was performed using the TaqMan Universal PCR Master Mix (Invitrogen AG, Basel, Switzerland) with a concentration of primers and probes of 1,000 and $200 \mathrm{nM}$, respectively in a final reaction volume of $25 \mu \mathrm{l}$ in an MX 4,000 (Stratagene) according to the manufacturer's protocol. PCR amplification was performed for 50 cycles. PCR 
Table 1 Sequences of primers and probes used for quantification of mRNA production by real-time RT-PCR

\begin{tabular}{|c|c|c|c|}
\hline $\begin{array}{l}\text { Canine hormone } \\
\text { receptor }\end{array}$ & $\begin{array}{l}\text { GeneBank accession } \\
\text { number }\end{array}$ & Sequences of primers and probes & $\begin{array}{l}\text { Amplicon } \\
\text { length }\end{array}$ \\
\hline LH & AF389885 & $\begin{array}{l}\text { 5'-AAACCAAAGGCCAGTATTATAACCA-3' (sense) } \\
\text { 5'-AGTGAAAAAGCCAGCTGCACTAC-3' (antisense) } \\
\text { 5'-CCCACTCCCTGTCTGCCAGTCTATGG-3' (probe) }\end{array}$ & $78 \mathrm{bp}$ \\
\hline FSH & M65085 & $\begin{array}{l}\text { 5'-GTGGAGATTTTTCTCTGCAAATG -3' (sense) } \\
\text { 5'-CAGGAGCAGGGCCATAATT-3' (antisense) } \\
\text { 5'-TCATCCATCCACCTGCTTTCTTCCT-3' (probe) }\end{array}$ & $71 \mathrm{bp}$ \\
\hline GnRH & AF206513 & $\begin{array}{l}\text { 5'-TCTGCAAAGTCCTCAGCTATCTG-3' (sense) } \\
\text { 5'-GGCTGATCACTACCATCATGAAG-3' (antisense) } \\
\text { 5'-GCTTTTCTCCATGTATGCCCC-3' (probe) }\end{array}$ & $74 \mathrm{bp}$ \\
\hline
\end{tabular}

Sequences of primers and probes for the canine hormone receptors were designed in-house from published sequences using the PrimerExpress software (Applied Biosystems, Rotkreuz, Switzerland). Primers and probe for the housekeeping gene r18 s (ribosomal RNA) were purchased as predeveloped Control Reagents (Applera Europe B.V., Rotkreuz, Switzerland)

amplification of the constitutively expressed r18 S gene was used as a measure of input RNA and thus to normalize the mRNA levels. The results are expressed as threshold cycle (CT), which is defined as the cycle number at which the PCR product crosses the threshold of detection. They are calculated according to the manufacturer's protocol (User Bulletin No. 2, Applied Biosystems). Threshold cycles lower than 40 were considered positive. Canine ovary and pituitary gland was used as positive control tissue. Since it is not known which tissue could serve as negative control we used cultured keratinocytes instead. Control experiments using RNA samples without reverse transcription were performed to demonstrate absence of possible contaminating genomic DNA.

The obtained amplicons were sequenced to confirm homology with the respective sequence of the receptors. In addition the sequences were blasted using the basic local alignment search tool (BLAST) at the National Center for Biotechnology Information (NCBI), National Library of Medicine (http://www. ncbi.nlm.nih.gov/cgi-bin/BLAST/Blast.cgi) to exclude homologies with other sequences than the specific receptors.

\section{Immunohistochemistry}

For IHC the following primary antibodies were used: polyclonal goat anti human GnRH receptor (Santa Cruz Biotechnology; Santa Cruz, CA, catalogue No. sc8682), polyclonal goat anti human LH receptor (Santa Cruz Biotechnology; Santa Cruz, CA, catalogue No. sc26341), polyclonal rabbit anti-FSHr (Zymed Laboratories Inc., San Francisco, CA, catalogue No. 18-2258). As negative controls for the GnRH- and the LH-receptor the respective blocking peptides (Santa Cruz Biotechnology; Santa Cruz, CA, catalogue No. sc-8682 P and No. sc-26341 P) were used. Rabbit IgG protein
(Zymed Laboratories Inc., San Francisco, CA, Catalogue No. 02-6102) was used as negative control for the FSHR. For immunostaining of the FSHR the DakoCytomation LSAB 2 System-HRP, code No. K0672 kit was used.

After deparaffinzing and hydrating the sections they were stained as follows:

FSHR Endogenous peroxidase was quenched by incubating the section in $\mathrm{H}_{2} \mathrm{O}_{2}$ (diluted 1:10 in methanol, $30 \mathrm{~min}$ ). After rinsing in tap water slides were blocked with BSA ( $0.5 \%$ in PBS/TBS, $30 \mathrm{~min}$ ) before the specimen was incubated with the primary antibody (1:150 in PBS, overnight, $4^{\circ} \mathrm{C}$ ). This step was followed by sequential incubation with a biotinylated link antibody for $30 \mathrm{~min}$ and horseradish peroxidase streptavidin for $30 \mathrm{~min}$. Staining was completed by incubation with AEC Substrate-Chromogen for approximately 5 min. Between each incubation step slides were washed twice for $5 \mathrm{~min}$ in PBS.

LHR Endogenous peroxidase was quenched by incubating the section in $0.075 \% \mathrm{HCl}$ in ethanol for $15 \mathrm{~min}$. After rinsing in tap water the slides were blocked with horse serum (20\% in TBS/Tween, $10 \mathrm{~min}$ ) before the specimen was incubated with the primary antibody 1:100 diluted in $\mathrm{TBS} / \mathrm{T}$ ween, $30^{\circ} \mathrm{C} 70 \mathrm{~min}$ ). This step was followed by incubation with a mouse anti goat horseradish peroxidase conjugate (1:150 in TBS/ Tween, $1 \mathrm{~h}$ ). Staining was completed by incubation with AEC Substrate-Chromogen for approximately 10 min. Between each incubation step slides were washed twice for $5 \mathrm{~min}$ in TBS.

GnRHR Endogenous peroxidase was quenched by incubating the section in $\mathrm{H}_{2} \mathrm{O}_{2}$ (1:10 in methanol, $15 \mathrm{~min}$ ). After rinsing in tap water the slides were blocked $(0.5 \%$ BSA-PBS/TBS, $20 \mathrm{~min})$ before the 
specimen was incubated with the primary antibody (1:40 diluted in PBS, $1 \mathrm{~h} 45 \mathrm{~min}$ ). This step was followed by incubation with a mouse anti goat horseradish peroxidase conjugate (1:40 in PBS, $30 \mathrm{~min})$. Staining was completed by incubation with AEC Substrate-Chromogen for approximately $20 \mathrm{~min}$. Between each incubation step slides were washed twice for $5 \mathrm{~min}$ in PBS.

Positive staining of all receptors resulted in a redcolored precipitate at the antigen site. Slides were counterstained with Ehrlichs hematoxylin and mounted in GVA.

\section{Results}

\section{Real-time RT PCR}

For the first time we were able to detect and quantify mRNA of GnRH-, FSH-, and LH-receptors in canine skin and bladder biopsies. Linearity of mRNA expression and primer efficacy was assessed with serial dilutions of the input amount of cDNA and is shown in the standard curves of Figs. 1, 2 and 3 for GnRHR, LHR,

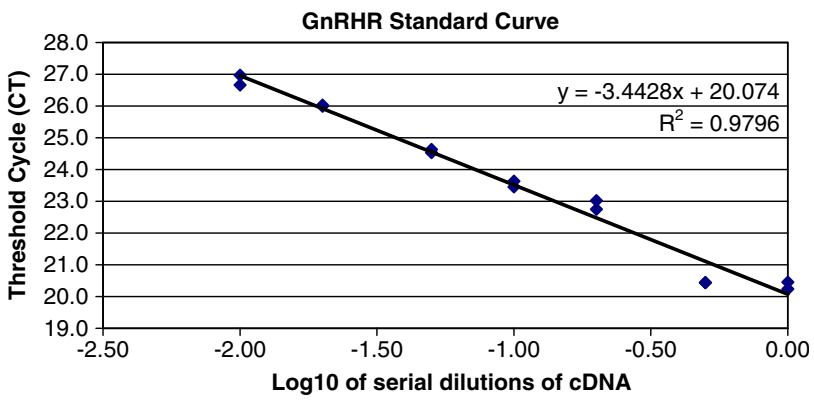

Fig. 1 Linearity assessment of mRNA expression using serial dilutions of input cDNA reverse transcribed from canine pituitary gland

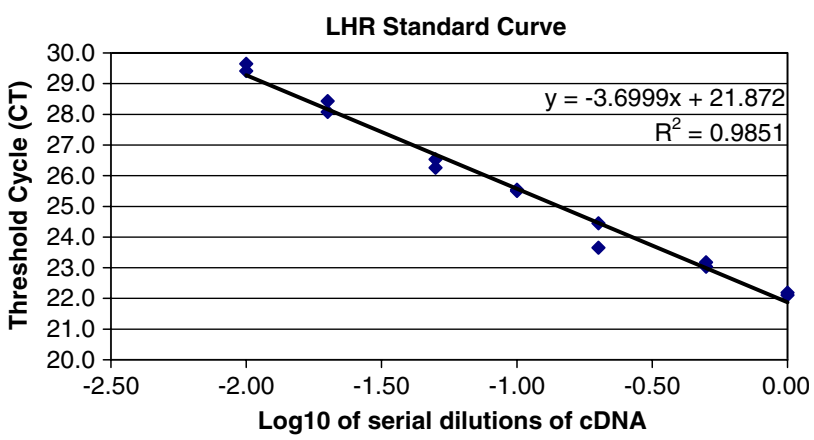

Fig. 2 Linearity assessment of mRNA expression using serial dilutions of input cDNA reverse transcribed from canine ovary

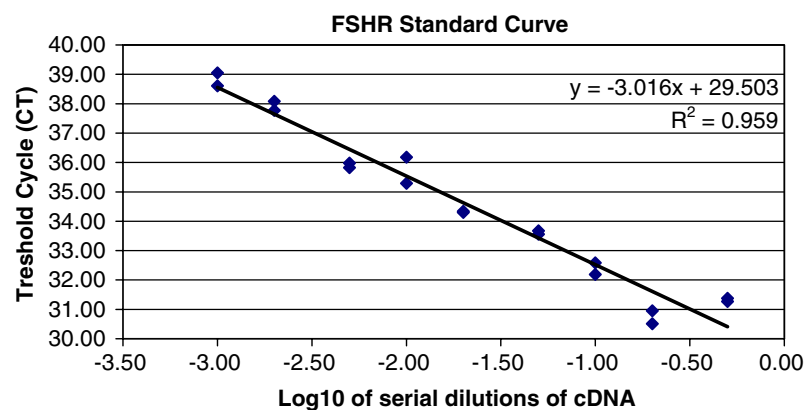

Fig. 3 Linearity assessment of mRNA expression using serial dilutions of input cDNA reverse transcribed from canine ovary

and FSHR, respectively. The homology of the obtained amplicons with the respective sequence of the receptors was confirmed by DNA sequencing. Furthermore we could prove with the Blast database search program that the sequence of the GnRHR and LHR amplicons showed a $100 \%$ homology with the respective hormone receptors of the dog and a high homology with the respective sequence of other species. The sequence of the canine FSHR is not published yet and primers and probes were designed from the known human sequence. Homology of the obtained amplicon with the human sequence was $97 \%$. The amplicon of the LHR was not only $100 \%$ homologous with the respective sequence of the canine receptor but also with some bacterial and viral sequences (AF458082.1, AF035003.2, AJ288592.1, AJ288588.1, AJ288587.1, AJ288585.1, AY680862.1, AY429544.1, AJ431219.1, AJ431214.1, AJ308478.1, AJ786617.1, AJ311600.1). The mean and the range of the CT values of the skin and urinary bladder biopsies as well as from the control tissues are shown in Table 2.

Immunohistochemistry

Immunohistochemical studies showed that GnRH-, FSH-, and LH-receptors are expressed in canine urinary bladder and in canine skin. In the urinary bladder the transitional epithelium and the smooth muscles are labelled. Furthermore a positive staining for FSR receptor was also seen in the connective tissue of the Lamina propria. Positive cells show a diffuse cytoplasmic staining. Examples for positive staining and lack of staining in negative controls in canine urinary bladder are depicted in Fig. 4. All three hormone receptors are detectable in the epidermis, the sebaceous- and sweat glands, as well as in the arrector pili muscles. In the hair follicles positive staining of all three receptors was noted in the infundibulum and in the isthmus. No difference in the staining intensity was noted between anagen and telogen follicles in the above mentioned anatomic locations. The inner 
Table 2 Mean and range of CT values of skin and bladder biopsies and controls

\begin{tabular}{llll}
\hline Tissue & CT value and range & & GnRHR \\
\cline { 2 - 4 } & LHR & FSHR & $36.08(34.05-38.33)$ \\
\hline Skin & $33.57(29.81-36.23)$ & $37.89(33.04-42.84)$ & $44.73(36.06-50.00)$ \\
Urinary bladder & $31.12(28.58-33.75)$ & $34.68(31.69-37.40)$ & $34.94(33.07-35.76)$ \\
Pituitary gland (positive control) & $27.35(26.43-28.37)$ & $30.21(28.51-31.86)$ & $22.02(20.67-23.07)$ \\
Ovary (positive control) & $21.63(19.79-26.97)$ & $50(50)$ & $27.13(23.58-28.79$ \\
Keratinocytes (negative control) & $50(50)$ & $35.89(34.64-37.13)$ \\
\hline
\end{tabular}

root sheath of the upper portion of the bulb stains positively for GnRH- and LH-receptors, whereas the outer root sheath stains for all three receptors. The lower portion of the outer root sheath, the dermal papilla and the matrix cells stain only for LHR. As in the urinary bladder positive cells show a diffuse cytoplasmic staining with the exception of the glycogen rich cells outer root sheath cells where positive labeling for GnRHR is marginating the cytoplasmic membrane. Examples for positive staining and negative controls in canine skin are shown in Fig. 5. Furthermore all three hormone receptors are detectable in the muscular layer of the blood vessels in urinary bladder and skin. Negative controls are negative in the skin and the urinary bladder.

The intensity of the labeling within the cells and the number of positively stained cells was graded semiquantitatively in the urinary bladder and the skin and is scored as absent $(-)$, weak $(+)$, moderate $(++)$, and strong $(+++)$. In Table 3 the mean of the two obtained values (final score) is depicted.

\section{Discussion}

To our knowledge investigations of the distribution of GnRH-, FSH-, and LH-receptors in canine skin and urinary bladder have not been performed previously. The present work demonstrates that mRNA for these receptors is expressed in these tissues and that the corresponding proteins are present as well.

We were able to show that mRNA expression of GnRH-, FSH-, and LH receptors can be quantified by real-time PCR and that the sequence of the GnRHR and LHR amplicons showed a 100\% homology with the respective hormone receptors of the dog. So far the sequence of the canine FSHR is not published yet but our amplicon shows a 97\% homology with the human receptor and a high primer efficacy was shown in canine tissue. Unfortunately the amplicon of the LHR was not only $100 \%$ homologous with the respective sequence of the canine receptor but also with some bacterial and viral sequences. However, since we do not expect these sequences in canine skin or urinary bladder the real-time PCR can still be regarded as highly specific.

Obtained CT values for the FSHR in the urinary bladder were low in some tissue samples and negative in others (range 36.06-50), although PCR performance regarding sensitivity was appropriate as shown in the positive control. These results suggest that individual dogs do not express FSHR in the urinary bladder which might be a consequence of a different production of primary regulatory hormones. Longterm keratinocytes were used as negative control for the real-time PCR and CT values were negative for LHR and FSHR. However, results were positive for GnRHR suggesting that supraordinate hormones are still produced after prolonged cell culture.

Immunohistochemical studies showed that GnRH-, FSH-, and LH-receptors were present in the skin. In humans it has been demonstrated that LHR immunolabeling is present in various epidermal structures. In this human study in the epidermis the basal, spinous, and granular cell layers were stained, whereas no receptors were detected in the stratum corneum. In the anagen hair, immunostaining was found in the inner root sheath below the level of the sebaceous glands and in the outer root sheath above this level. In the telogen follicle, only the latter staining was observed. In the sebaceous glands only the thin cells close to the walls of the ducts were immunolabelled. In the ecrine sweat glands, the external clear cells were stained in the secretory portion of the gland, whereas only the cells close to the lumen were stained in the ducts (Venencie et al. 1999). Our findings on immunolabeling of the LHR are in partial agreement with the findings in this study. In our study we could demonstrate positive labeling also in the outer root sheath of the upper bulb and all sebocytes stained positively. Furthermore we found positive staining for FSHR in the epidermis and adnexa. In contrast monoclonal antibodies raised against human FSHR failed to detect the latter in 

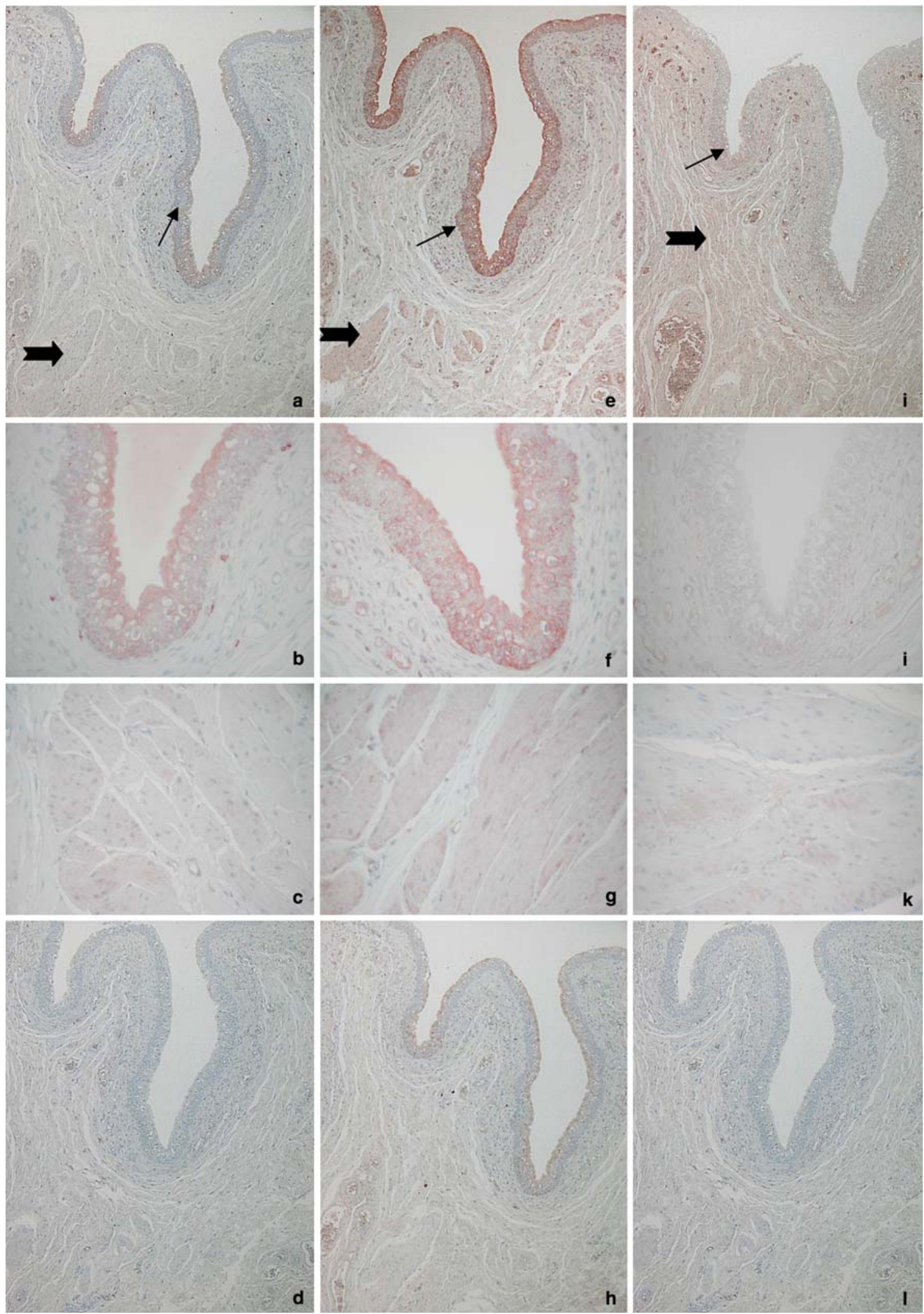

human skin (Venencie et al. 1999). To our knowledge no reports concerning GnRH-receptors in the skin exist.
In the urinary bladder an intense labeling of the transitional epithelium was observed with the antibody raised against the LHR and a weak staining was pres- 
Fig. 4 a Immunohistochemical labeling for the GnRH-receptor in the urinary bladder. Note the moderate staining of the transitional epithelium (small arrow) and the faint staining of the smooth muscles (broad arrow). As indicated in the table muscles located deeper in the bladder wall stained moderately $(\times 100)$. b Higher magnification of the transitional epithelium $(\times 400)$. c Higher magnification of the of the smooth muscles $(\times 400)$. d Negative control for the GnRH-receptor $(\times 100)$. e Immunohistochemical labeling for the LH-receptor in the urinary bladder. Note the strong staining of the transitional epithelium (small arrow) and of the smooth muscles (broad arrow) $(\times 100)$. f. Higher magnification of the transitional epithelium $(\times 400)$. g Higher magnification of the of the smooth muscles $(\times 400)$. h Negative control for the LH-receptor $(\times 100)$. i Immunohistochemical labeling for the FSH-receptor in the urinary bladder. Note the absent staining of the transitional epithelium (small arrow) and the absent to mild staining of the connective tissue of the Lamina propria (broad arrow). As indicated in the table muscles located deeper in the bladder wall stained mild to moderately $(\times 100)$ j. Higher magnification of the transitional epithelium $(\times 400)$. k Higher magnification of the smooth muscles $(\times 400)$. I Negative control for the FSH-receptor $(\times 100)$
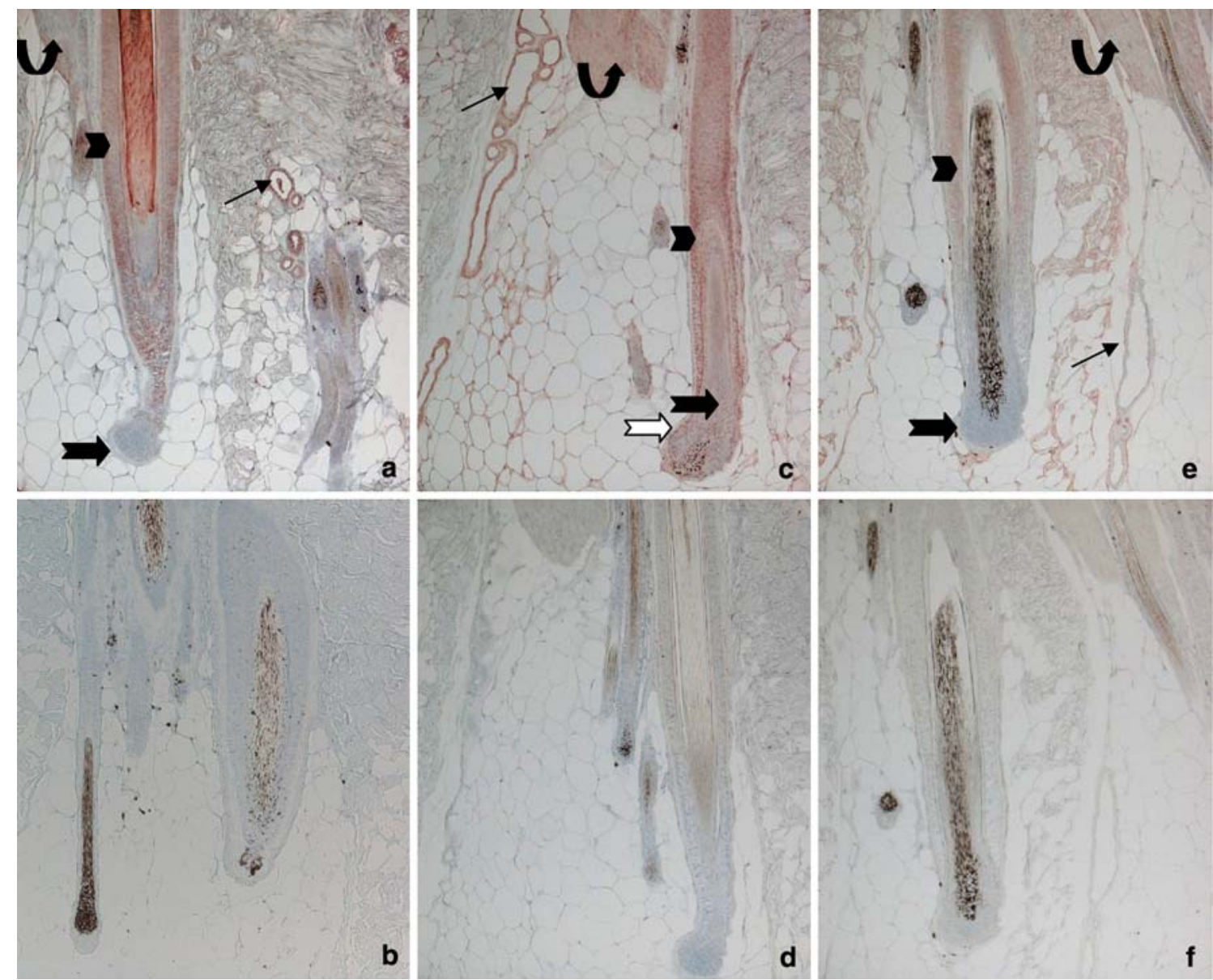

Fig. 5 a Immunohistochemical labeling for the GnRH-receptor in the canine skin. Note the strong staining of the upper portion of the outer root sheath (arrow head), the sweat glands (small arrow) and the arrector pili muscle (curved arrow). Staining is absent in the hair bulb (broad arrow) b Negative control for the GnRH-receptor $(\times 100)$. c Immunohistochemical labeling for the LH-receptor in the canine skin. Note the strong staining of the upper portion of the outer root sheath (arrow head), the lower portion of the outer root sheath (empty arrow), the sweat glands (small arrow) and the arrector pili muscle (curved arrow). Staining is mild in the hair bulb (broad arrow) d Negative control for the Lhreceptor $(\times 100)$. e Immunohistochemical labeling for the FSH-receptor in the canine skin. Note the moderate staining of the upper portion of the outer root sheath (arrow head) and the arrector pili muscle (curved arrow). Labeling is absent in the sweat glands (small arrow) and the hair bulb (broad arrow). As indicated in the table sweat glands in other areas stained mildly positive. f Negative control for the FSH-receptor $(\times 100)$ ent with antibodies against the FSH- and GnRH receptors. All antibodies stained the smooth muscles in the urinary bladder. It has been suggested that high LH levels after menopause may be involved in increased pelvic floor disorders, a common condition in postmenopausal women, since smooth muscles are an important compartment of the pelvic floor (Brown et al. 1999). A further indication that the expression of LHR 
Table 3 Immunohistochemical labelling of GnRH-, FSH- and $\mathrm{LH}-$ receptors in canine urinary bladder and in canine skin

\begin{tabular}{llll}
\hline Location & GnRHR & FSHR & LHR \\
\hline Bladder & & & \\
Transitional epithelium & ++ & - & +++ \\
Lamina propria & - & $(+)$ & - \\
Smooth muscles & ++ & $+(+)$ & +++ \\
Skin & & & \\
Epidermis & + & + & +++ \\
Infundibulum & + & + & ++ \\
Isthmus & ++ & ++ & +++ \\
Hair bulb, inner root sheath & ++ & - & ++ \\
Hair bulb, outer root sheath, & +++ & ++ & +++ \\
upper portion & & & \\
Hair bulb, outer root sheath, & - & - & +++ \\
lower portion & & & \\
Follicular papilla & - & - & + \\
Matrix cells & - & - & + \\
Sebaceous glands & +++ & ++ & +++ \\
Sweat glands & +++ & + & +++ \\
Arrector pili muscles & ++ & ++ & +++ \\
Muscular layer of vessels in & ++ & + & + \\
skin and bladder & & & \\
\hline
\end{tabular}

could play a role in the side effects after spaying and menopause, respectively, is the fact that in urinary bladders of menopausal women significant lower mRNA levels for LHR were demonstrated than in cycling women (Tao et al. 1998). To our knowledge so far no studies have been performed to demonstrate GnRH-, and FSH receptors in the urinary bladder of human beings.

Our data provide the fundamentals to examine the distribution of FSH-, LH-, and GnRH-receptors in canine skin and urinary bladder and to assess gene activity at the transcriptional level by real-time RTPCR. This enables us in future studies to assess the quantity of hormone receptors and the corresponding histological changes in the skin and the urinary bladder before and after spaying and thus gain more insight into the pathogenesis of side effects due to spaying.

Acknowledgments This work was financially supported by a research grant from the Vetsuisse Faculty.

\section{References}

Ashley PF, Frank LA, Schmeitzel LP, Bailey EM, Oliver JW (1999) Effect of oral melatonin administration on sex hormone, prolactin, and thyroid hormone concentrations in adult dogs. J Am Vet Med Assoc 215:1111-1115

Blauer M, Vaalasti A, Pauli SL, Ylikomi T, Joensuu T, Tuohimaa P (1991) Location of androgen receptor in human skin. J Invest Dermatol 97:264-268

Brown JS, Grady D, Ouslander JG, Herzog AR, Varner RE, Posner SF (1999) Prevalence of urinary incontinence and associated risk factors in postmenopausal women. Heart \&
Estrogen/Progestin Replacement Study (HERS) Research Group. Obstet Gynecol 94:66-70

Bukovsky A, Indrapichate K, Fujiwara H, Cekanova M, Ayala ME, Dominguez R, Caudle MR, Wimalsena J, Elder RF, Copas P, Foster JS, Fernando RI, Henley DC, Upadhyaya NB (2003) Multiple luteinizing hormone receptor (LHR) protein variants, interspecies reactivity of anti-LHR mAb clone 3B5, subcellular localization of LHR in human placenta, pelvic floor and brain, and possible role for LHR in the development of abnormal pregnancy, pelvic floor disorders and Alzheimer's disease. Reprod Biol Endocrinol 1:46

Choudhry R, Hodgins MB, Van der Kwast TH, Brinkmann AO, Boersma WJ (1992) Localization of androgen receptors in human skin by immunohistochemistry: implications for the hormonal regulation of hair growth, sebaceous glands and sweat glands. J Endocrinol 133:467-475

Hasselquist MB, Goldberg N, Schroeter A, Spelsberg TC (1980) Isolation and characterization of the estrogen receptor in human skin. J Clin Endocrinol Metab 50:76-82

Holt PE, Thrusfield MV (1993) Association in bitches between breed, size, neutering and docking, and acquired urinary incontinence due to incompetence of the urethral sphincter mechanism. Vet Rec 133:177-180

Hsueh AJ, Bicsak TA, Jia XC, Dahl KD, Fauser BC, Galway AB, Czekala N, Pavlou SN, Papkoff H, Keene J, et al (1989) Granulosa cells as hormone targets: the role of biologically active follicle-stimulating hormone in reproduction. Recent Prog Horm Res 45:209-273; discussion 273-207

Jennes L, Dalati B, Conn PM (1988) Distribution of gonadrotropin releasing hormone agonist binding sites in the rat central nervous system. Brain Res 452:156-164

Kaiser UB, Conn PM, Chin WW (1997) Studies of gonadotropinreleasing hormone (GnRH) action using GnRH receptorexpressing pituitary cell lines. Endocr Rev 18:46-70

Kakar SS, Musgrove LC, Devor DC, Sellers JC, Neill JD (1992) Cloning, sequencing, and expression of human gonadotropin releasing hormone $(\mathrm{GnRH})$ receptor. Biochem Biophys Res Commun 189:289-295

Khan H, Jiang LG, Jayashree GN, Yarney TA, Sairam MR (1997) Recognition of follicle stimulating hormone (alphasubunit) by a recombinant receptor protein domain coded by an alternately spliced mRNA and expressed in Escherichia coli. J Mol Endocrinol 19:183-190

Liang T, Hoyer S, Yu R, Soltani K, Lorincz AL, Hiipakka RA, Liao S (1993) Immunocytochemical localization of androgen receptors in human skin using monoclonal antibodies against the androgen receptor. J Invest Dermatol 100:663-666

Mowszowicz I, Kopp F, Martin PM (1982) Multiple steroid binding sites in human skin cytosol. Br J Dermatol 107(Suppl 23):60-61

Olson PN MJ, Nett TM. (1992) Concentrations of luteinizing hormone and follicle-stimulating hormone in the serum of sexually intact and neutered dogs. Am J Vet Res 53:762-766

Orth J, Christensen AK (1977) Localization of 125I-labeled FSH in the testes of hypophy-sectomized rats by autoradiography at the light and electron microscope levels. Endocrinology 101:262-278

Pabon JE, Bird JS, Li X, Huang ZH, Lei ZM, Sanfilippo JS, Yussman MA, Rao CV (1996) Human skin contains luteinizing hormone/chorionic gonadotropin receptors. J Clin Endocrinol Metab 81:2738-2741

Perrin MH, Bilezikjian LM, Hoeger C, Donaldson CJ, Rivier J, Haas Y, Vale WW (1993) Molecular and functional characterization of GnRH receptors cloned from rat pituitary and a mouse pituitary tumor cell line. Biochem Biophys Res Commun 191:1139-1144 
Reichler IM, Hubler M, Jochle W, Trigg TE, Piche CA, Arnold S (2003) The effect of GnRH analogs on urinary incontinence after ablation of the ovaries in dogs. Theriogenology 60:1207-1216

Reichler IM PE, Piche CA, Jochle W, Roos M, Hubler M et al (2004) Changes in plasma gonadotropin concentrations and urethral closure pressure in the bitch during the 12 months following ovariectomy. Theriogenology 62:1391-1402

Reichler IM, Hung E, Jochle W, Piche CA, Roos M, Hubler M, Arnold S (2005) FSH and LH plasma levels in bitches with differences in risk for urinary incontinence. Theriogenology 63:2164-2180

Scott DW, Miller WH, Griffin CE (2001) Endocrine and metabolic diseases. 6th edn. WB Saunders, Philadelphia
Sun PD, Davies DR (1995) The cystine-knot growth-factor superfamily. Annu Rev Biophys Biomol Struct 24:269-291

Tao YX, Heit M, Lei ZM, Rao CV (1998) The urinary bladder of a woman is a novel site of luteinizing hormone-human chorionic gonadotropin receptor gene expression. Am J Obstet Gynecol 179:1026-1031

Venencie PY, Meduri G, Pissard S, Jolivet A, Loosfelt H, Milgrom E, Misrahi M (1999) Luteinizing hormone/human chorionic gonadotrophin receptors in various epidermal structures. Br J Dermatol 141:438-446

Wise P (1999) Neuroendocrine modulation of the "menopause": insights into the aging brain. Am J Physiol 277:E965-970 